\title{
Genetic investigation of the large-scale escape of a tropical fish, barramundi Lates calcarifer, from a sea-cage facility in northern Australia
}

\author{
T. H. Noble ${ }^{*}$, C. Smith-Keune, D. R. Jerry \\ Centre of Sustainable Tropical Fisheries and Aquaculture and School of Marine and Tropical Biology, \\ James Cook University, Townsville 4811, Queensland, Australia
}

\begin{abstract}
Expansion of sea-cage aquaculture has increased incidences of large-scale escapes of farmed fish. Whilst escape events are relatively well-characterised for temperate fish species, such as salmonids, there are no studies that report the occurrence and persistence of farmed tropical fish escapees. Given the rapid rise in tropical finfish aquaculture, there is a need to understand the persistence of escaped farmed tropical species so that informed risk assessments in the planning of future sea-cage aquaculture developments can be made. In 2011, a barramundi Lates calcarifer sea-cage facility in Hinchinbrook Channel, Queensland, was destroyed by a tropical cyclone, resulting in the escape of $\sim 280 \mathrm{t}$ of $\geq 500 \mathrm{~mm}$ fish into the surrounding wild population. Between 12 and 18 mo after the escape event, 403 genetic samples were collected from barramundi caught within Hinchinbrook Channel. DNA parentage analyses were used to assign sampled fish as either 'farm escapees' or 'wild' by matching microsatellite genotypes to the hatchery broodstock used to produce seedstock for the farm. Following parentage analysis, fish identified as escapees comprised $31 \%$ of the sampled barramundi population. A single male-female broodstock pairing accounted for $32 \%$ of the escaped fish identified. The allelic richness of escapees was $56 \%$ of that observed in wild barramundi, while the average pairwise relatedness of escapees was $0.164( \pm 0.003)$ versus $0.002( \pm 0.001)$ within wild fish. This study is the first to show that farm barramundi can survive and integrate into natural populations in large numbers up to at least 18 mo after they escape. Due to the large proportion of escapee fish currently in the Hinchinbrook Channel population and their high levels of relatedness, longer-term concerns are raised over potential accumulation of inbreeding effects. This makes ongoing monitoring and documentation of impacts critical to quantify the true effects these large escape events in this tropical fish have on wild populations.
\end{abstract}

KEY WORDS: Farm escapee - Sea-cage aquaculture $\cdot$ Genetic impact $\cdot$ Parentage $\cdot$ Barramundi Lates calcarifer

\section{INTRODUCTION}

Due to declining wild fisheries and increasing demand for fish protein, aquaculture is now recognised as the fastest growing primary industry globally (FAO 2010). This industry expansion has led to increasing development and exploitation of previously unexploited aquatic environments, such as coastal seas

${ }^{*}$ Corresponding author: tansyn.noble@my.jcu.edu.au and open oceans, giving rise to a growing coastal and marine sea-cage aquaculture industry (Tacon \& Halwart 2007). The increasing number and production intensity of sea-cage farms, including throughout Asia (Merican 2006), has raised concerns regarding the possible impacts of large-scale escape events of farmed fish on wild populations. In particular, there is increasing consternation regarding possible negative

() The authors 2014. Open Access under Creative Commons by Attribution Licence. Use, distribution and reproduction are unrestricted. Authors and original publication must be credited. 
long-term genetic impacts through interbreeding of aquaculture escapees with wild fish (Hindar et al. 1991, Gross 1998, Naylor \& Burke 2005, Glover 2010). For example, experimental studies show that captivebred Atlantic salmon Salmo salar do interbreed with wild conspecifics in nature, albeit less successfully (Fleming et al. 2000, McGinnity et al. 2003), and farmed fish escapes have altered the genetic profiles of receiving wild salmon populations (Crozier 1993, Skaala et al. 2006).

Farmed and wild fish populations typically display marked differences in their genetic composition because of a number of hatchery processes, including founder effects (Norris et al. 1999, Skaala et al. 2004), low effective breeding population sizes (Frost et al. 2006) and domestication selection (Christie et al. 2012). These processes often result in low genetic diversity, low allelic richness, high rates of genetic drift and high levels of genetic relatedness amongst hatchery bred individuals compared to wild populations. Large-scale fish escape events have the potential to cause immediate swamping of natural/wild gene pools with distinct and highly related genotypes, potentially compromising the genetic integrity of the receiving wild population if the escaped fish survive to become established breeders. Furthermore, temperate-water salmonid studies suggest that integration of hatchery bred individuals may be detrimental to the overall fitness of natural populations due to the poorer performance in fitness traits often observed in hatchery bred fish compared with wild fish (Araki et al. 2008). Interbreeding between farm Atlantic salmon and wild salmon have resulted in the farm individuals exhibiting lower reproductive success and reduced survival than wild salmon (Fleming et al. 2000). Findings from a further study of Atlantic salmon in Ireland (McGinnity et al. 2003) were similar to those of Fleming et al. (2000); however, differences in survival between hatchery and wild offspring were primarily observed in early life stages. Therefore, information on an aquaculture species' ability to persist and introgress into wild populations is essential for predicting potential negative impacts to wild populations and for developing informed risk-assessment policies.

Current knowledge on the genetic effects of farmed fish escapees stems primarily from temperate aquaculture species like salmon Salmo spp. and European sea bass Dicentrarchus labrax (Hindar et al. 1991, Naylor et al. 2005, Toledo Guedes et al. 2009). Many temperate water fishes, salmonids especially, often differ in their life history characteristics and reproductive biology compared to tropical spe- cies (Johannes 1978). Characteristics such as upstream reproductive migration in anadromous salmonids and limited reproductive output are likely to limit the level of introgression of escaped farmed temperate fishes. Conversely, many tropical marine fishes, like barramundi, are tolerant of a wide range of environmental parameters, are highly fecund and often reproduce repeatedly throughout their lifetime. Additionally, in sex-changing species such as barramundi that have overlapping generations, escaped individuals may reproduce as both males and females, and without dispersal, the likelihood of breeding with close relatives could increase. The occurrence of sex change may add further concern over potential impacts of escapees if a facility stocks cages with different aged cohorts of fish sharing the same or similar parentage, such as having nursery and grow out cages stocked from the same hatchery. Consequently, there is a critical gap in understanding the risks posed by escapes of tropical marine fish species, and often, in fact, risk assessments for tropical sea-cage aquaculture are reliant on extrapolation of impacts from highly divergent temperate species such as salmonids (Kerrod Beattie, QDAFF, pers. comm.).

Lates calcarifer, commonly known as barramundi in Australia and as Asian seabass in Asia, is a large euryhaline fish found throughout the Indo-West Pacific. Barramundi are protandrous hermaphrodites, maturing first as males at around 550 to $600 \mathrm{~mm}$ ( $\sim 3$ yr old) and then later as females, generally once they have reached $850 \mathrm{~mm}$-although some females have been reported at lengths below $680 \mathrm{~mm}$ in some areas (Davis 1982). Barramundi typically show limited coastal movement $(<20 \mathrm{~km})$; however, larger intra-riverine movements associated with downstream migration to spawning grounds are common (Russell et al. 2013). Barramundi in Australia display moderate population genetic structure (Shaklee et al. 1993, Keenan 1994, Chenoweth et al. 1998), with the most comprehensive study showing an average $F_{\mathrm{ST}}$ of 0.064 among Australian barramundi populations (Keenan 1994). There are 16 distinct genetic stocks described across northern Australia, with Queensland containing 6 broad stocks along its coastline.

Barramundi are one of the major species farmed in coastal sea-cages throughout the tropics, including East and Southeast Asia and northern Australia (De Silva \& Phillips 2007, Rimmer \& Ponia 2007). In northern Australia specifically, plans for expansion of the industry are underway, with several new barramundi sea-cage aquaculture developments under consideration (Northern Territory Department Primary Industries pers. comm., Queensland Department of Agri- 
culture Forestry and Fisheries pers. comm.). Sea-cage aquaculture of barramundi is based on hatchery produced fingerlings stocked into sea-cages for grow out, generally from locally sourced broodstock. Hatchery production of barramundi fingerlings is through communal spawning of sexually matured broodstock that are induced to spawn generally via artificial manipulation using hormones or environmental conditions (De Jesus-Ayson \& Ayson 2013). The mass spawning nature of barramundi means there is very little control over parental contribution or specific crosses. Additionally, as barramundi are sequential hermaphrodites, male broodstock have to be replaced once they begin to change sex, and this replacement is conducted either using wild sources or growing hatchery produced fish. However, the above characteristics of barramundi hatchery production limit the industry's ability to undertake selective breeding programs; therefore, fingerlings that are stocked into sea-cages are generally F1 or F2 progeny.

Barramundi sea-cage farming is restricted to tropical regions that often experience adverse weather conditions, such as intense storms, king tides and cyclones. Such weather conditions can cause extensive damage to sea-cage infrastructure, leading to large-scale escapes of farm fish. For example, in Australia, several barramundi sea-cage facilities have experienced large-scale releases of fish due to adverse weather conditions within the last $15 \mathrm{yr}$. In 2006, as a result of particularly large king tides and storm activity, tens of thousands (the exact number was undisclosed) of farmed barramundi escaped into the waters around the Tiwi Islands, Northern Territory (www.nt.gov.au/d/news_media_archive_article. $\mathrm{cfm}$ ?newsid=63\&ws=1), raising concerns from conservationists about the impact this large escape event would have on local barramundi populations. Unfortunately, the genetic and ecological impacts that this large escape event may have had have never been investigated. More recently, in February 2011, a severe cyclone destroyed a barramundi farm located in Hinchinbrook Channel, north Queensland, Australia. Approximately $140000 \quad(\sim 280$ t) sub-adult barramundi, $\sim 500 \mathrm{~mm}$ in length, escaped from the destroyed sea-cages along with an unquantified number of fingerlings that escaped from nursery cages (Kerrod Beattie, QDAFF, pers. comm.). Due to the large-scale nature of this escape event and the potential for significant genetic impacts on the adjacent wild barramundi population, concerns were raised regarding the persistence of escaped fish in the environment and the genetic risk posed by these escaped individuals over the longer term.
In light of the growing sea-cage industry throughout south-east Asia and Australia, knowledge of the prevalence and persistence of escaped tropical fish species such as barramundi is vital if we are to move forward from risk assessments that are based on salmonid species. Accordingly, to address this knowledge gap, DNA parentage techniques were applied to establish the persistence and prevalence of escaped barramundi derived from the Hinchinbrook Channel sea cage facility up to 18 mo after their escape into the wild. The genetic diversity and relatedness of the escaped fish were characterised along with that of the receiving wild barramundi population. We further characterised the family diversity represented in the escaped cohorts of fish to better understand the potential for future inbreeding risk. This is the first study that provides a baseline to begin to identify the possible genetic impacts of farm escapees of a tropical marine fish species based on a case study involving a large scale barramundi escape event in North Queensland, Australia.

\section{MATERIALS AND METHODS}

\section{Study area}

Hinchinbrook Channel runs between the Australian mainland and Hinchinbrook Island in tropical north Queensland (Fig. 1). The channel extends some $50 \mathrm{~km}$ along the coastline, encompassing many creeks and tributaries, including Conn Creek in which the barramundi sea-cage facility was located. Hinchinbrook Channel is closed to commercial net fishing; however, it supports a large recreational fishery and connects to neighbouring catchments that are open to commercial fisheries. The population size of barramundi within Hinchinbrook Channel is unknown, although this species is considered to be naturally abundant and is a major recreational fish species. Annual fishing competitions are dedicated to catching this species and are a key tourism drawcard for the local community.

\section{Sample collection}

Commercial and recreational fishers were engaged in this project and donated barramundi genetic samples both from within the Hinchinbrook Channel (recreational catch) and from neighbouring creeks along the coast (recreational and commercial catch). In total, 403 barramundi were caught and sampled 


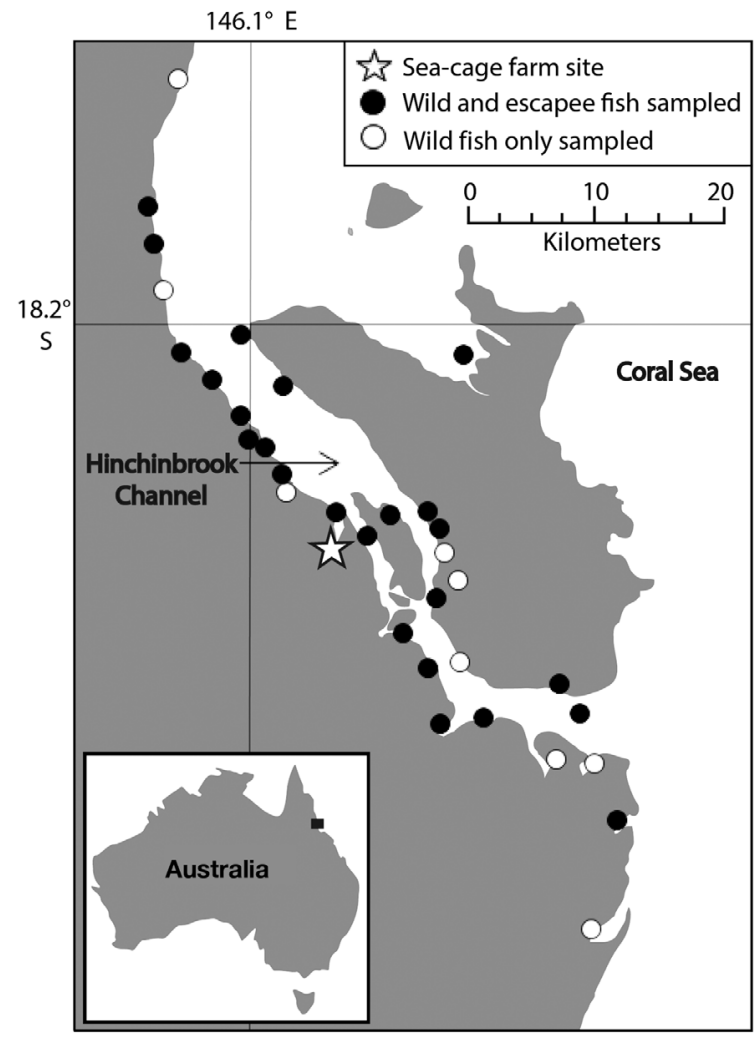

Fig. 1. Hinchinbrook Channel showing the location of the farm site where barramundi Lates calcarifer escaped and sample catch locations of escapee and wild fish identified through DNA parentage analysis

from throughout the Hinchinbrook Channel. Collection sites spanned $\sim 70 \mathrm{~km}$ along the neighbouring coastline, including Hinchinbrook Channel and Conn Creek. Sample collection covered the range of area where the escapee fish were suspected to have travelled, given movement of barramundi is primarily restricted to distances less than $20 \mathrm{~km}$ (Russell et al. 2013). Fishers provided a small tissue sample from all barramundi caught and recorded the size $(\mathrm{mm})$ and approximate catch position of each fish sampled on a map. Genetic samples were preserved in DMSO-salt solution (20\% DMSO, 0.25 M EDTA, $\mathrm{pH} 8$, in a saturated $\mathrm{NaCl}$ solution) or $80 \%$ ethanol. The samples collected from Hinchinbrook Channel were collected during a 6 mo period, 12 to $18 \mathrm{mo}$ after the escape event. The escaped barramundi were considered unlikely to have undergone breeding in the time between release and sampling due to their immature age and because the majority of fish sampled (average length: $605 \mathrm{~mm}$ ) were substantially larger than that expected of a $1 \mathrm{yr}$ old barramundi if spawning had occurred. Therefore, it was highly unlikely that introgressed offspring of escaped barramundi were sampled in the present study.
The barramundi hatchery supplier to the sea-cage farm was known, and DNA samples of all broodstock held by the hatchery $(\mathrm{n}=34)$ were sampled previously as part of a genetic audit. The 34 broodstock were made up of 12 females and 22 males (derived from hatchery records), and assignment tests showed that according to the defined population structure of Australian barramundi from Chenoweth et al. (1998), the broodstock originated from within the same genetic stock present where the escape event took place (T. H. Noble et al. unpubl. data). Due to the mass spawning nature of barramundi, all broodstock were included as potential parents of the farm escapees.

\section{Genomic DNA extraction and microsatellite analyses}

Genomic DNA (gDNA) was extracted from the barramundi samples using a modified $1 \% \mathrm{~N}$-cetyl $\mathrm{N}, \mathrm{N}, \mathrm{N}$-trimethylammonium bromide (CTAB) chloroform/isoamyl extraction protocol (Adamkewicz \& Harasewych 1996). DNA was checked for quality and quantity on $0.8 \%$ agarose gels by electrophoresis prior to dilution for genetic marker amplification. In total, 17 microsatellite loci were amplified in 2 multiplexed polymerase chain reactions (PCR) (the P1 and G suites; see Table 1). The P1 multiplex suite amplified 9 microsatellite loci (Lca008, Lca020, Lca021, Lca058, Lca064, Lca069, Lca070, Lca074 and Lca098) and was modified from Zhu et al. (2006), while the G suite amplified 8 microsatellite loci (Lca003, Lca016, Lca040, Lca055, Lca154, Lca178, Lca287 and Lca371) using a variety of published primer sequences from various sources (Table 1) (Yue et al. 2001, 2002, Wang et al. 2006, Zhu et al. 2006). All reactions were conducted in a $10 \mu \mathrm{l}$ total volume containing fluorescently labelled primers at varying concentrations (Table 1), $1 \times$ TypeIT microsatellite PCR master mix (Qiagen Taq DNA polymerase, $1 \times$ buffer, $3 \mathrm{mM}$ $\mathrm{MgCl}_{2}$ and $0.2 \mathrm{mM}$ dNTPs) and $\sim 2 \mathrm{ng} \mathrm{\mu l}^{-1}$ gDNA. PCR conditions for both marker suites were: 1 cycle of $95^{\circ} \mathrm{C}$ for $5 \mathrm{~min}$ followed by 10 cycles of $95^{\circ} \mathrm{C}$ for $30 \mathrm{~s}, 57^{\circ} \mathrm{C}$ for $90 \mathrm{~s}$, and $72^{\circ} \mathrm{C}$ for $30 \mathrm{~s}$ followed by 20 cycles of $95^{\circ} \mathrm{C}$ for $30 \mathrm{~s}, 55^{\circ} \mathrm{C}$ for $90 \mathrm{~s}$, and $72^{\circ} \mathrm{C}$ for $30 \mathrm{~s}$ and concluding with a final step of $60^{\circ} \mathrm{C}$ for 30 min. Successful amplification was verified via agarose gel electrophoresis on a $1.5 \%$ agarose gel prior to purification of PCR products using MicroCLEAN reagent (MicroZone).

Microsatellite genotypes of the samples were determined by fragment analysis on an Applied Bio- 
Table 1. Summary of microsatellite marker suites and associated primers to genotype barramundi Lates calcarifer including original source of primer sequences and relevant PCR conditions, final primer concentrations and fluorescent labels utilised in the present study

\begin{tabular}{|lccccc|}
\hline Locus & Motif & $\begin{array}{c}\text { Marker } \\
\text { suite }\end{array}$ & $\begin{array}{c}\text { Final primer } \\
\text { concentration } \\
(\mu \mathrm{M})\end{array}$ & $\begin{array}{c}\text { Observed allele } \\
\text { size range } \\
(\mathrm{bp})\end{array}$ & Source \\
\hline Lca03 & $(\mathrm{CA})_{\mathrm{n}}$ & $\mathrm{G}$ & 0.1 & $216-239$ & Yue et al. (2001) \\
Lca16 & $(\mathrm{CA})_{\mathrm{n}}$ & $\mathrm{G}$ & 0.2 & $255-283$ & Yue et al. (2002) \\
Lca40 & $(\mathrm{GT})_{\mathrm{n}}$ & $\mathrm{G}$ & 0.2 & $122-141$ & \\
Lca57 & $(\mathrm{GT})_{\mathrm{n}}$ & $\mathrm{G}$ & 0.2 & $207-222$ & Zhu et al. (2006) \\
Lca154 & $(\mathrm{TG})_{\mathrm{n}}$ & $\mathrm{G}$ & 0.1 & $144-154$ & Wang et al. (2006) \\
Lca178 & $(\mathrm{GA})_{\mathrm{n}}$ & $\mathrm{G}$ & 0.2 & $434-446$ & \\
Lca287 & $(\mathrm{TC})_{\mathrm{n}}$ & $\mathrm{G}$ & 0.2 & $169-213$ & \\
Lca371 & $(\mathrm{CA})_{\mathrm{n}}$ & $\mathrm{G}$ & 0.2 & $375-387$ & \\
Lca08 & $(\mathrm{GA})_{\mathrm{n}}$ & P1 & 0.2 & $253-260$ & Zhu et al. (2006) \\
Lca20 & $(\mathrm{CA})_{n}$ & P1 & 0.8 & $129-142$ & \\
Lca21 & $(\mathrm{CA})_{\mathrm{n}}$ & P1 & 0.8 & $183-195$ & \\
Lca58 & $(\mathrm{GT})_{n}$ & P1 & 0.24 & $402-459$ & \\
Lca64 & $(\mathrm{AC})_{\mathrm{n}}$ & P1 & 0.2 & $279-313$ & \\
Lca69 & $(\mathrm{GT})_{n}$ & P1 & 1.28 & $356-361$ & \\
Lca70 & $(\mathrm{CAG})_{n}$ & P1 & 0.64 & $297-313$ & \\
Lca74 & $(\mathrm{CA})_{n}$ & P1 & 1.28 & $163-170$ & \\
Lca98 & $(\mathrm{TG})_{n}$ & P1 & 1.2 & $189-213$ & \\
& & & & & \\
\hline
\end{tabular}

typed were also excluded from further analyses $(\mathrm{n}=18)$.

Based on allelic diversity data from sampled fish, the power of the microsatellite markers used in the study to discriminate between individuals was tested in GenAlEx 6.41 (Peakall \& Smouse 2006) using the probability of identity (PI) function. This function estimates the average probability of 2 unrelated individuals from within the 1 sample set having identical multilocus genotypes (Peakall \& Smouse 2006). Using this function, the expected probability of unrelated individuals having the same multilocus genotypes over the 16 loci utilised in the Hinchinbrook Channel sample set was $2.6 \times 10^{-8}$. Therefore, the microsatellites utilised have high discriminatory power, and it is statistically improbable any 2 individuals sampled from Hinchinbrook Channel would share the same genotypes over all 16 loci.

systems (ABI) 3730 DNA Analysis System at a commercial genetic analysis facility (Georgia Genomics Facility, USA). Included with each PCR sample was the GeneScan 500 LIZ ladder (Applied Biosystems). Final allele scoring was performed using GeneMarker 2.2.0 software (Soft Genetics). A positive control sample was included on each plate of genotypes to ensure consistency, as well as a negative control to ensure no significant contamination had occurred.

Microsatellite markers are particularly prone to genotyping errors (Hess et al. 2012), which can occur at multiple stages throughout sample processing. A common approach to estimating genotyping error rates is independently re-genotyping a subset of samples (Hess et al. 2012, Glover et al. 2012). A total of 41 (10\% of samples) barramundi samples were genotyped twice in separate PCR reactions, and genotypes were compared to estimate the error rate in the present study. The genotyping error rate was $0.2 \%$. Microsatellite genotypes were also checked for the occurrence of null alleles, stuttering and large allele drop-out using Micro-Checker 2.2.3 (Van Oosterhout et al. 2004). Occurrence of null alleles was identified in 1 microsatellite locus (Lca287) as an excess of homozygotes. This marker was subsequently removed from all genotypic data sets before further analyses were undertaken, leaving 16 microsatellites for the analyses. Samples with $<14$ loci
Given that many of the barramundi caught by recreational fishers were sampled and then released, there was the possibility that the same fish could be recaptured and sampled more than once. An identity check was therefore also performed to check for duplicated samples on all barramundi sampled from Hinchinbrook Channel as well as broodstock genotypes from the hatchery known to have produced fingerlings used to stock the farm using the software Cervus 3.0.3 (Kalinowski et al. 2007). Within the Hinchinbrook Channel samples, 2 instances of identical genotypes under different sample IDs were identified, likely representing fish that had been sampled twice (i.e. recaptured). Only 1 representative genotype was retained in both instances. No identical genotypes were found within the broodstock samples. After all quality assurance checks, of the 403 barramundi sampled, 383 samples were successfully genotyped at $\geq 14$ loci, resulting in an overall genotyping coverage of $99.7 \%$, and were subsequently used for genetic analyses.

\section{Identification of escapees by parentage analysis}

Barramundi sampled from Hinchinbrook Channel were characterised as either offspring of hatchery broodstock or wild fish, using a DNA parentage 
analysis approach. Cervus 3.0.3 (Kalinowski et al. 2007) was used to perform the parentage analyses. First, a simulation of the parentage analysis using parent pairs was carried out to assess the exclusionary power of the series of microsatellite loci used to assign parentage and to estimate critical values of log-likelihood statistics for assessing confidence in parentage assignments. The combined non-exclusion probability of the set of loci used was $6.08 \times 10^{-6}$. The simulation was based on the allele frequencies of the hatchery broodstock only, given that only the parents of the farm escapees were sampled (hatchery broodstock) and the parents of the wild fish were unknown. Therefore, the proportion of parents sampled for barramundi genotyped in Hinchinbrook Channel was estimated. Here, a sensitivity analysis was conducted using 3 different estimates $(0.01,0.1$ and 0.2 ) of the proportion of candidate parents sampled. Increasing the estimated proportion caused the number of assignments with strict confidence (95\%) to decline slightly (by 4); however, the most likely parent pair remained the same. The lowest estimate of 0.01 was used as this estimate was thought to be the most conservative, minimising the likelihood of wild fish being misclassified as escapees due to forced assignments to hatchery broodstock. The parentage analysis of Hinchinbrook Channel samples and hatchery broodstock was then performed.

The single most-likely candidate mother (dam) and father (sire) were identified using confidence levels and number of mismatching loci between the parent pair and offspring. Only high confidence assignments $(\geq 95 \%)$ with zero allele mismatches across all 16 microsatellite loci between the parent pair and offspring were accepted as indicative of escapees. All other individuals that were not assigned using the strict criteria above were categorised as wild fish.

\section{Statistical analyses}

Genetic variation was compared among the 3 groups (hatchery broodstock, farm escapees and wild barramundi) using standard genetic diversity indices. Deviations from Hardy-Weinberg equilibrium (HWE) and linkage disequilibrium (LD) were tested for the identified escapees and all wild fish using Genepop 4.0.10 (Raymond \& Rousset 1995, Rousset 2008). Significance values for HWE and LD tests were adjusted using sequential Bonferroni correction to account for multiple comparisons and the increased probability of committing a Type I error (Rice 1989). Calculations of allele frequencies, total number of alleles, mean num- ber of alleles per locus, observed heterozygosity and expected heterozygosity under HWE expectations were performed using GenAlEx 6.41 (Peakall \& Smouse 2006). Allelic richness was calculated for individuals identified as escapees or wild fish using FSTAT 2.9.3 (Goudet 2001). Pairwise estimates of relatedness (Queller \& Goodnight 1989) were calculated using the program CoAncestry (Wang 2011). Expected relatedness values using the Queller \& Goodnight (1989) estimate are $r=0.5$ for full siblings, $r=0.25$ for half siblings, and $\mathrm{r}=0$ for unrelated individuals. A test of population differentiation (pairwise $F_{\mathrm{ST}}$ ) between escapees and wild Hinchinbrook Channel barramundi was also performed. $F_{\text {ST }}$ was calculated using Weir \& Cockerham's (1984) algorithm in Arlequin 3.5 (Excoffier \& Lischer 2010), and confidence levels were estimated by 1000 permutations of the dataset.

\section{RESULTS}

\section{Identification of farm escapees}

In total, 119 of the 383 Hinchinbrook Channel barramundi samples were unambiguously assigned as progeny of the hatchery broodstock (i.e. putative aquaculture escapees). Those assigned to broodstock had zero allelic mismatches with the parent pair, whilst the fish deemed to be wild ranged from 1 to 7 mismatches. Accordingly, almost a third (31\%) of barramundi within the size class of fish sampled (250 to $950 \mathrm{~mm}$ ) in the Hinchinbrook Channel population were of farm origin.

\section{Genetic differences observed between farm escapees and wild barramundi}

A number of differences in levels of genetic diversity were observed between the escapee and wild barramundi population sampled in Hinchinbrook Channel. Genotypes of the escaped fish population did not conform to Hardy-Weinberg expectations overall and at 4 of the 16 loci, whereas all loci were in HWE within the wild barramundi sample. Linkage disequilibrium was also observed in $37 \%$ (34 of 120) of loci comparisons within the escapees (compared to $<1 \%$ in wild barramundi). These deviations are expected and often observed in hatchery produced fish where non-random matings and high familial relatedness occurs.

The escapee barramundi population possessed lower allelic diversity than the wild and the source 
broodstock populations, tested separately (Table 2, Table S1 in the Supplement at www.int-res.com/ articles/suppl/q005p173_supp.pdf). The total number of alleles observed in the farm escapees was 56 compared to a possible 80 in the hatchery broodstock and 109 in the wild barramundi. Allelic richness, which adjusts the mean number of alleles for varying sample sizes, was compared between the escapee, wild barramundi and hatchery broodstock. Allelic richness was also substantially lower in the escapee fish compared with the hatchery broodstock and wild fish, $3.49 \pm 0.41$ vs. $5.00 \pm 0.69$ and $5.06 \pm 0.64$, respectively (Table 2). An estimate of genetic dissimilarity between the farm escapees and wild barramundi in Hinchinbrook Channel was provided by the population differentiation statistic $F_{\mathrm{ST}}$, which was estimated over all 16 loci to be 0.038 ( $\mathrm{p}<0.001)$. Of particular concern, however, was the high level of relatedness of escapees compared to wild barramundi (Table 2). Among fish identified as farm escapees, the average pairwise relatedness between individuals was $0.164( \pm 0.003)$; this level of relatedness is representative of first cousins. The level of relatedness among the hatchery broodstock and among wild fish was $-0.001( \pm 0.009)$ and $0.002( \pm 0.001)$, respectively, indicating the hatchery broodstock were unrelated to one another, as were the wild fish.

\section{Family diversity of farm escapees}

DNA parentage analyses identified 21 half-sib families represented among the sample of barramundi determined to be farm escapees. However, a single full-sib family accounted for $32 \%$ of all escapees sampled. This indicated that nearly a third of the escapees were full siblings. In addition, 2 other families each contributed $\sim 15 \%$ of sampled escapees (Fig. 2). In contrast, 9 of the identified families had only 1 representative sampled. From the total number of broodstock $(n=34)$ held at the hatchery, parentage analysis identified that only 12 broodstock contributed to the escapees sampled (Fig. 2). However, as is often seen in hatchery barramundi produced cohorts, the level of

Table 2. Genetic diversity and relatedness statistics observed in barramundi Lates calcarifer identified as farm escapees or wild fish. Genetic diversity statistics of broodstock from the hatchery used to stock farm sea-cages are also provided for comparison. Included is the total number of alleles, mean (SE in parentheses) number of alleles (NA), allelic richness (AR), observed heterozygosity $\left(H_{\mathrm{o}}\right)$, expected heterozygosity $\left(H_{\mathrm{e}}\right)$ and average pairwise relatedness $(\mathrm{r})$ over 16 microsatellite loci. $\mathrm{n}$ : number of fish in each category

\begin{tabular}{|lcccccrrr}
\hline & $\mathrm{n}$ & $\begin{array}{c}\text { Total no. } \\
\text { of alleles }\end{array}$ & NA & AR & $H_{\mathrm{o}}$ & $H_{\mathrm{e}}$ & $\mathrm{r}$ \\
\hline Escapee barramundi & 119 & 56 & $3.56(0.42)$ & $3.49(0.41)$ & $0.58(0.05)$ & $0.51(0.05)$ & $0.164(0.003)$ \\
Hatchery broodstock & 34 & 80 & $5.00(0.69)$ & $5.00(0.69)$ & $0.56(0.05)$ & $0.56(0.04)$ & $-0.001(0.009)$ \\
Wild barramundi & 264 & 109 & $6.75(0.88)$ & $5.06(0.64)$ & $0.56(0.04)$ & $0.55(0.04)$ & $0.002(0.001)$ \\
\hline
\end{tabular}

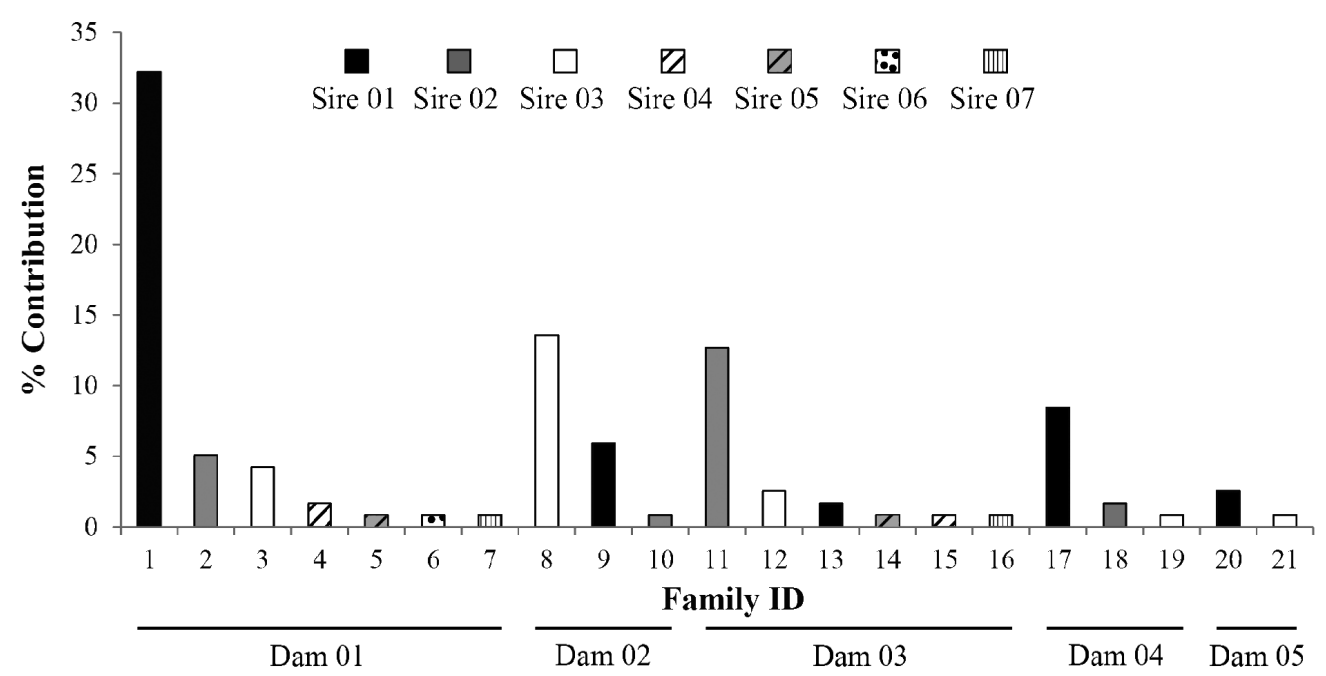

Fig. 2. Family contributions represented in the barramundi Lates calcarifer farm escapees as percentage of individuals assigned using all hatchery broodstock as candidate parents with zero mismatches across 16 microsatellite loci and 95\% confidence. Solid lines along the $x$-axis link families with a common dam, and bar shading and patterning represent different sires 

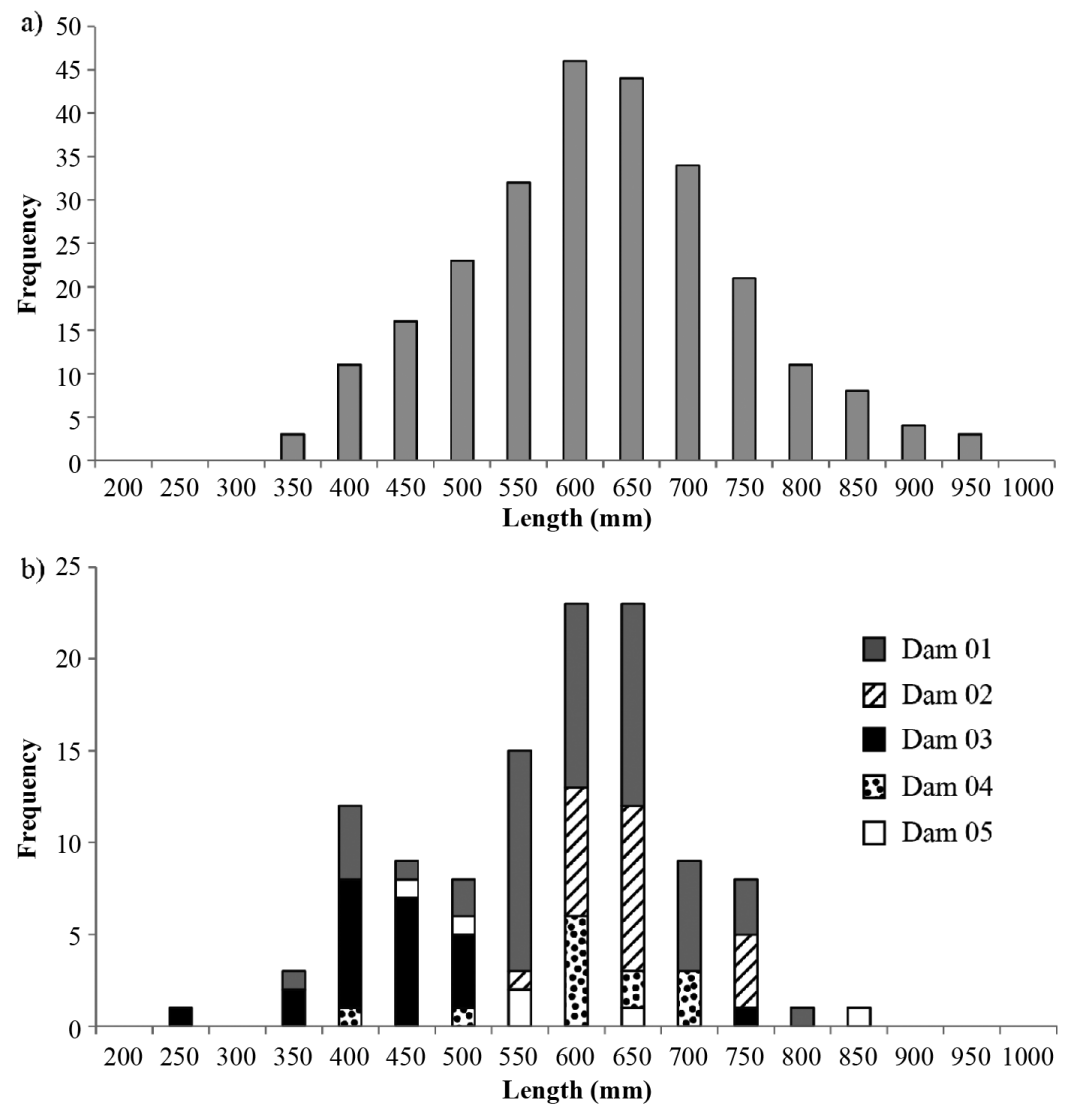

Fig. 3. Length-frequency histogram of barramundi identified by DNA analyses as (a) wild and (b) escapee fish sampled from Hinchinbrook Channel. Also shown (b) is the contribution from the hatchery dams to escapee barramundi over the size distribution tions in each size range, supports anecdotal reports that in addition to the escape of preadult sized fish, an unquantified number of juveniles also escaped. There was some overlap of dam contribution among the 2 size cohorts, with Dam 01 and to a lesser extent Dams 02 and 04 represented in both of the size cohorts, signifying there are halfsiblings and potentially full-siblings dispersed amongst the 2 size cohorts. Despite this, a higher portion of escapees sampled were in the larger size range of 550 to $750 \mathrm{~mm}$, representing the expected size of pre-adult fish that had escaped from grow out cages.

Finally, catch location information gathered from fishers showed that fish identified as farm escapees had dispersed throughout the Hinchinbrook Channel from the original location of the destroyed sea-cage farm. The present study was restricted to sampling within the confines of the Hinchinbrook Channel and neighbouring coast, but within the region sampled, the escapee barramundi were found to have moved up to $30 \mathrm{~km}$ from the former farm site in 24 of the 33 sampling locations, indicating substantial dispersion of escapees away from the farm site (Fig. 1).

\section{DISCUSSION}

contribution amongst broodstock was highly variable. Of the 5 dams contributing to the escapees, a single dam (Dam 01) contributed 46\%, with Dams 02 and 03 contributing 20 and $19.5 \%$, respectively (Fig. 2). Similarly, of the 7 sires identified as having sired escapees, Sire 01 dominated the contribution to the escapees, with $51 \%$ of escapees assigned to this sire (Fig. 2). Also, Sires 02 and 03 fathered 20 and $22 \%$ of escapees, respectively.

\section{Dispersal and size distribution of escapee and wild barramundi}

The size distribution of barramundi identified as being of wild origin followed a normal distribution centred around a mean length of $602 \mathrm{~mm}$, with the majority of fish caught being in the 550 to $750 \mathrm{~mm}$ size range (Fig. 3a). The size frequency of the escapees was more bimodal (Fig. 3b). The bimodal distribution observed in the escapees, along with the appearance of 2 different sets of broodstock contribu-
The current study is the first within the literature to report the persistence and prevalence of a tropical farmed fish species after a major sea-cage escape event. This unique opportunity arose from the escape of >140000 barramundi from a sea-cage facility destroyed during cyclonic conditions. Because of the existence of source broodstock genotypes, DNA parentage assignment techniques could be successfully applied to identify farm escapees from wild barramundi. Based on sampling 18 mo after the seacage facility was destroyed, our analyses indicate that a high proportion of escaped barramundi of varying sizes and related genealogies survived and are now resident within Hinchinbrook Channel. We found $31 \%$ of the total population within the size classes sampled was of farm origin. These escaped fish were highly related and were derived from relatively few broodstock. Furthermore, the size/age variability and half-sib familial relationship of escapees of varying sizes suggests that related fish may 
sex change at different times, exacerbating the potential for inbreeding should reproduction between half-sibs of different sexes occur. The study also found that escaped fish had become established in the natural environment and had become widely dispersed within the Hinchinbrook Channel. Establishment of baseline information on the prevalence and genetic background of the escaped barramundi can now be used in the future to identify introgressed fish resulting from escapee/wild matings and to examine potential long-term genetic impacts of the escapee event on the wild population (i.e. inbreeding levels, phenotypic fitness data, etc.). The current baseline information, if combined with ongoing monitoring, will be critical to better inform risk assessment of seacage aquaculture for this emerging tropical aquaculture species and other similar species in the future.

A major concern of aquaculture escapees is the possibility of interbreeding between escapee and wild fish. Over the long term, the introgression of escapee fish into wild populations can alter the genetic profile of the wild population by lowering genetic diversity and driving changes in allele frequencies. Given that the broodstock used to produce the escapee fish are from within the same genetic stock as the Hinchinbrook Channel barramundi, the escapee fish possess similar alleles to those within the receiving wild population. However, the high proportion of escapee barramundi only represents a very narrow and highly related gene pool, with skewed allelic frequencies. Successful introgression of escapee barramundi may therefore swamp the wild population with highly related and potentially maladapted genotypes, conceivably leading to lower overall genetic diversity within the wild population, the loss of rare alleles and an increase in the level of inbreeding $\left(F_{\mathrm{IS}}=0.067\right.$ in the next generation if equal and random mating of escapee and wild fish is assumed and in the proportions evident within Hinchinbrook Channel; Wang 2011) due to the disproportionate contribution of related genotypes in spawning events.

So far, evidence illustrating genetic changes in receiving wild populations caused by escapee fish is highly variable, and there is no conclusive evidence demonstrating farm escapees caused lower overall genetic diversity of wild populations. However, several studies have demonstrated temporal genetic changes in Atlantic salmon populations in heavily farmed regions of Norway (Skaala et al. 2006, Glover et al. 2012, 2013). One of the main findings of all 3 studies was reduced genetic differentiation among populations compared to historical samples of the same populations. Most recently, Glover et al. (2013) have shown that the populations displaying these genetic changes have become more similar to farmed Atlantic salmon strains over time, and all 3 studies above conclude that the genetic changes observed were a result of introgression from farm escapees. Given that these changes have occurred with salmon, it is highly likely that due to the magnitude of the escape event reported herein, over time, similar reductions in genetic differentiation may be observed in Hinchinbrook Channel barramundi due to introgression of farmed genotypes into the wild barramundi gene pool.

Successful introgression of aquaculture escapees depends, among other factors, on their ability to reproduce within the population and to pass on their genes to future generations. Reproductive success of farmed salmon is far less than that of wild conspecifics under natural spawning conditions (Fleming et al. 2000, McGinnity et al. 2003). Farmed salmon have been highly selected over multiple generations for production traits under intensive hatchery conditions, and this may account for their overall lowered reproductive fitness when they escape into the wild. Whether this lowered reproductive fitness can be extrapolated to other farmed fishes like barramundi is not known, particularly for those species where little genetic selection has occurred. However, even in the highly selected Atlantic salmon strains, levels of introgression of farmed genes into wild population has still been high, with Glover et al. (2013) reporting levels of introgression of up to $47 \%$ within some salmon populations. Barramundi, however, unlike salmon, have not been subjected to decades of intensive selective breeding for traits that may genetically correlate with lowered reproductive fitness. Typically, barramundi broodstock are still F0 or F1 generation. Therefore, it is quite conceivable that levels of introgression of farmed barramundi escapees may be greater than those observed in salmon. Barramundi are a robust and highly fecund species, with a large female capable of producing tens of millions of eggs (Davis 1984). Barramundi are also broadcast spawners and can continue to reproduce throughout their life for more than a decade. These biological characteristics suggest that the reproductive output from barramundi escapees over their lifetime may be far greater than what is typically seen in salmon, and consequently, the overall potential for introgression among farmed and wild barramundi might be higher. To address this concern an understanding of the effects on reproductive fitness of interbreeding between the farm escapees and wild barramundi is urgently needed. 
The occurrence of sex change in barramundi may also increase potential breeding between siblings and close-relatives over the long term. Given the high average relatedness between escapees along with the likelihood of sex change in the future and spatial/temporal overlap of half-sib families, one of the most important aspects of this escape event is the potential for increased occurrence and accumulation of inbreeding within the Hinchinbrook Channel barramundi population. Furthermore, the evidence from barramundi tagging studies that indicate large coastal movements are relatively uncommon - with movement primarily restricted to distances between 5 and $20 \mathrm{~km}$ (Russell et al. 2013) — adds to the possibility of inbreeding accumulating within the wild barramundi population. Even if the escapee fish migrate out of Hinchinbrook channel, dilution will not occur quickly due to the restricted migratory behaviour of barramundi. Additionally, potential dilution through egg dispersal is low because larvae hatch $\sim 18 \mathrm{~h}$ after fertilisation (De Jesus-Ayson et al. 2013), and soon thereafter, larvae become motile and move into adjacent nursery habitat (Russell 2013).

This study is the first to characterise in detail the genetic foundations of an aquaculture escape event in a tropical species. We have highlighted substantial genetic differences between the escaped farm barramundi and wild barramundi that have the potential to cause significant changes to the local genetic profile of wild barramundi in the longer term. In particular, given the high number of fish in the current population that are farmed fish, there will be future concerns about the effects of inbreeding and its associated fitness consequences. Consequently, within the Hinchinbrook barramundi population, there is an opportunity for future studies to track genetic changes overtime and to directly assess fitness consequences that might arise in order to increase our understanding of the true genetic impact of these large-scale fish escape events in tropical marine farmed fishes.

Acknowledgements. We thank the assistance of the numerous recreational and commercial fishers and other volunteers who helped acquire samples for this study, especially Geoff Snell and members of the Cardwell Sportfishing Club.

\section{LITERATURE CITED}

Adamkewicz SL, Harasewych MG (1996) Systematics and biogeography of the genus donax (Bivalvia: Donacidae) in eastern North America. Am Malacol Bull 13:97-103

Araki H, Berejikian BA, Ford MJ, Blouin MS (2008) Synthesis: fitness of hatchery-reared salmonids in the wild. Evol
Appl 1:342-355

Chenoweth SP, Hughes JM, Keenan CP, Lavery S (1998) Concordance between dispersal and mitochondrial gene flow: isolation by distance in a tropical teleost, Lates calcarifer (Australian barramundi). Heredity 80:187-197

Christie MR, Marine ML, French RA, Blouin MS (2012) Genetic adaptation to captivity can occur in a single generation. Proc Natl Acad Sci USA 109:238-242

> Crozier WW (1993) Evidence of genetic interaction between escaped farmed salmon and wild Atlantic salmon (Salmo salar L.) in a northern Irish river. Aquaculture 113:19-29

Davis TLO (1982) Maturity and sexuality in barramundi, Lates calcarifer (Bloch), in the Northern Territory and south-eastern Gulf of Carpentaria. Aust J Mar Freshwater Res 33:529-545

Davis TLO (1984) Estimation of fecundity in barramundi, Lates calcarifer (Bloch), using an automatic particle counter. Aust J Mar Freshwater Res 35:111-118

De Jesus-Ayson EG, Ayson F (2013) Reproductive biology of the Asian seabass, Lates calcarifer. In: Jerry DR (ed) Biology and culture of Asian seabass Lates calcarifer. CRC Press, Boca Raton, FL, p 67-76

De Jesus-Ayson EG, Ayson F, Thepot V (2013) Early development and seed production of Asian seabass, Lates calcarifer. In: Jerry DR (ed) Biology and culture of Asian seabass Lates calcarifer. CRC Press, Boca Raton, FL, p 16-30

De Silva SS, Phillips MJ (2007) A review of cage aquaculture: Asia (excluding China). FAO, Rome

Excoffier L, Lischer HE (2010) Arlequin suite ver 3.5: a new series of programs to perform population genetics analyses under Linux and Windows. Mol Ecol Resour 10: 564-567

FAO (Food and Agriculture Organization of the United Nations) (2010) The state of the world's fisheries and aquaculture 2010. FAO, Rome

Fleming IA, Hindar K, Mjolnerod IB, Jonsson B, Balstad T, Lamberg A (2000) Lifetime success and interactions of farm salmon invading a native population. Proc Biol Sci 267:1517-1523

Frost LA, Evans BS, Jerry DR (2006) Loss of genetic diversity due to hatchery culture practices in barramundi (Lates calcarifer). Aquaculture 261:1056-1064

Glover KA (2010) Forensic identification of fish farm escapees: the Norwegian experience. Aquacult Environ Interact 1:1-10

Glover KA, Quintela M, Wennevik V, Besnier F, Sorvik AG, Skaala O (2012) Three decades of farmed escapees in the wild: a spatio-temporal analysis of Atlantic salmon population genetic structure throughout Norway. PLoS ONE 7:e43129

> Glover KA, Pertoldi C, Besnier F, Wennevik V, Kent M, Skaala O (2013) Atlantic salmon populations invaded by farmed escapees: quantifying genetic introgression with a Bayesian approach and SNPs. BMC Genet 14:74-93

Goudet J (2001) FSTAT, a program to estimate and test gene diversities and fixation indices (version 2.9.3). Available from www.unil.ch/izea/softwares/fstat.html

- Gross MR (1998) One species with two biologies: Atlantic salmon (Salmo salar) in the wild and in aquaculture. Can J Fish Aquat Sci 55:131-144

Hess MA, Rhydderch JG, LeClair LL, Buckley RM, Kawase M, Hauser L (2012) Estimation of genotyping error rate from repeat genotyping, unintentional recaptures and known parent-offspring comparisons in 16 microsatellite 
loci for brown rockfish (Sebastes auriculatus). Mol Ecol Resour 12:1114-1123

- Hindar K, Ryman N, Utter F (1991) Genetic effects of cultured fish on natural populations. Can J Fish Aquat Sci 48:945-957

Johannes RE (1978) Reproductive strategies of coastal marine fishes in the tropics. Environ Biol Fishes 3:65-84

Kalinowski ST, Taper ML, Marshall TC (2007) Revising how the computer program CERVUS accommodates genotyping error increases success in paternity assignment. Mol Ecol 16:1099-1106

Keenan CP (1994) Recent evolution of population structure in Australian barramundi, Lates calcarifer (Bloch): an example of isolation by distance in one dimension. Aust $\mathrm{J}$ Mar Freshwater Res 45:1123-1148

McGinnity P, Prodohl P, Ferguson A, Hynes R and others (2003) Fitness reduction and potential extinction of wild populations of Atlantic salmon, Salmo salar, as a result of interactions with escaped farm salmon. Proc R Soc Lond B Biol Sci 270:2443-2450

Merican Z (2006) Marine finfish cage culture: some of the strengths, weaknesses, opportunities and threats facing this expanding yet fragmented industry in China and southeast Asia. Aqua Cult Asia Pacific 2:22-24

Naylor R, Burke M (2005) Aquaculture and ocean resources: Raising tigers of the sea. Annu Rev Environ Resour 30: $185-218$

Naylor R, Hindar K, Fleming IA, Goldburg R and others (2005) Fugitive salmon: assessing the risks of escaped fish from net-pen aquaculture. Bioscience 55:427-437

Norris AT, Bradley DG, Cunnigham EP (1999) Microsatellite genetic variation between and within farmed and wild Atlantic salmon (Salmo salar) populations. Aquaculture 180:247-264

Peakall ROD, Smouse PE (2006) Genalex 6: genetic analysis in Excel. Population genetic software for teaching and research. Mol Ecol Notes 6:288-295

Queller DC, Goodnight KF (1989) Estimating relatedness using genetic markers. Evolution 43:258-275

Raymond M, Rousset F (1995) GENEPOP (version 1.2): population genetics software for exact tests and ecumeniscism. Heredity 86:248-249

Rice WR (1989) Analysing tables of statistical tests. Evolution 43:223-225

Rimmer MA, Ponia B (2007) A review of cage aquaculture: Oceania. FAO, Rome

Rousset F (2008) GENEPOP '007: a complete reimplementation of the GENEPOP software for Windows and Linux. Mol Ecol Resour 8:103-106

Russell DJ (2013) Lates calcarifer wildstock: their biology, ecology and fishery. In: Jerry DR (ed) Biology and culture of Asian seabass Lates calcarifer. CRC Press, Boca Raton,

Editorial responsibility: Ian Fleming, St. John's,

Newfoundland and Labrador, Canada
FL, p 82-83

Russell DJ, Jerry DR, Thuesen PA, Thomson FE, Power TN, Smith-Keune C (2013) Fish stocking programs: assessing the benefits against potential long-term genetic and ecological impacts. Queensland Department of Agriculture, Fisheries and Forestry (QDAFF), Cairns

> Shaklee JB, Salini J, Garrett RN (1993) Electrophoretic characterization of multiple genetic stocks of barramundi perch in Queensland, Australia. Trans Am Fish Soc 122: 685-701

Skaala Ø, Høyheim B, Glover K, Dahle G (2004) Microsatellite analysis in domesticated and wild Atlantic salmon (Salmo salar L.): allelic diversity and identification of individuals. Aquaculture 240:131-143

> Skaala Ø, Wennevik V, Glover K (2006) Evidence of temporal genetic change in wild Atlantic salmon, Salmo salar L., populations affected by farm escapees. ICES J Mar Sci 63:1224-1233

Tacon AGJ, Halwart M (2007) Cage aquaculture: a global overview. In: Halwart M, Soto D, Arthur JR (eds) Cage aquaculture - regional reviews and global overview. FAO Fish Tech Pap, FAO, Rome, p 1-16

> Toledo Guedes K, Sánchez-Jerez P, González-Lorenzo G, Brito Hernández A (2009) Detecting the degree of establishment of a non-indigenous species in coastal ecosystems: sea bass Dicentrarchus labrax escapes from sea cages in Canary Islands (Northeastern Central Atlantic). Hydrobiologia 623:203-212

Van Oosterhout C, Hutchinson WF, Wills DPM, Shipley P (2004) Micro-checker: software for identifying and correcting genotyping errors in microsatellite data. Mol Ecol Notes 4:535-538

> Wang J (2011) Coancestry: a program for simulating, estimating and analysing relatedness and inbreeding coefficients. Mol Ecol Resour 11:141-145

Wang CM, Lo LC, Zhu ZY, Yue GH (2006) A genome scan for quantitative trait loci affecting growth-related traits in an f1 family of Asian seabass (Lates calcerifer). BMC Genomics 7:274

- Weir BS, Cockerham CC (1984) Estimating f-statistics for the analysis of population structure. Evolution 38:1358-1370

> Yue GH, Yang L, Orban L (2001) Characterization of microsatellites in the IGF-2 and GH genes of Asian seabass (Lates calcarifer). Mar Biotechnol (NY) 3:1-3

> Yue G, Li Y, Chao T, Chou R, Orban L (2002) Novel microsatellites from Asian sea bass (Lates calcarifer) and their application to broodstock analysis. Mar Biotechnol (NY) 4:503-511

Zhu ZY, Lin G, Lo LC, Xu YX, Feng F, Chou R, Yue GH (2006) Genetic analysis of Asian seabass stocks using novel polymorphic microsatellites. Aquaculture 256: $167-173$

Submitted: September 9, 2013; Accepted: April 30, 2014 Proofs received from author(s): June 18, 2014 